\title{
GALTON AND THE MENDELIAN RATIOS
}

\author{
F. A. LINTS and JEAN DELCOUR * \\ F. A. Janssens Memorial Laboratory for Genetics, Agricultural Institute of the \\ University, Heverlee-Louvain, Belgium
}

Received 20.ix.67

Olby (1965, 1966) claims that in a letter to Darwin, Galton clearly deduced the "Mendelian" ratios.

The relevant portion of the letter is as follows, the material in square brackets referring to this paper:

" Let us . . . suppose that in some particular . . structure, the hybrid between white and black forms was exactly intermediate, viz. gray,- thenceforward for ever. Then . . . in the hybrid, it would be either that some cells were white and others black; and nearly the same proportion of each (1) [fig. 1, $\mathrm{F}_{1}$, a] giving on the whole ... a uniform gray tint,-or (2) [fig. 1, $\left.\mathrm{F}_{1}, \mathrm{n}\right]$ each cell had a uniform gray tint.

"In (1) we see that each cell has been an organic unit (quoad colour). In other words, the structural unit is identical with the organic unit.

"In (2) the structural unit would not be an organic unit but it would be an organic molecule. It would have been due to the development, not of one gemmule but of a group of gemmules, in which the black and white species would, on statistical grounds, be equally numerous (as by the hypothesis, they were equipotent).

"The larger the number of gemmules in each organic molecule, the more uniform will the tint of grayish be in the different units of structure. It has been an old idea of mine, not yet discarded and not yet worked out, that the number of units in each molecule may admit of being discovered by noting the relative number of cases of each grade of deviation from the mean grayness. If there were two gemmules only, each of which might be either white or black, then in a large number of cases one-quarter would always be quite white, one-quarter quite black, and one-half would be gray. If there were three molecules, we should have 4 grades of colour (1 quite white, 3 light gray, 3 dark gray, 1 quite black and so on according to the successive lines of 'Pascal's triangle'). This way of looking at the matter would perhaps show $(a)$ whether the number in each given species of molecule was constant and $(b)$, if so, what those numbers were."

Dr Olby makes the following interpretations from this letter: "It is generally believed that before 1900 no one apart from Mendel suspected that the frequencies of the various classes in the $\mathrm{F}_{2}$ generation might approximate to simple ratios. It is, therefore, surprising to find that this is not the case, for . . . Francis Galton (1822-1911) . . . derived the 1:2:1 ratio deductively reasoning from the premise that inheritance is due to a finite number of persistent particles", and " here we find all the elements of the Mendelian explanation with the exception of independent assortment and germinal segregation". Finally, Dr Olby asked the following question: "Are the 'cases', to which he refers, the individuals resulting from a given cross or the members of an outbreeding and heterogeneous population?"

These remarks in turn merit some comments.

First of all it seems clear that Galton's 1:2:1 ratio, unlike Mendel's, does 


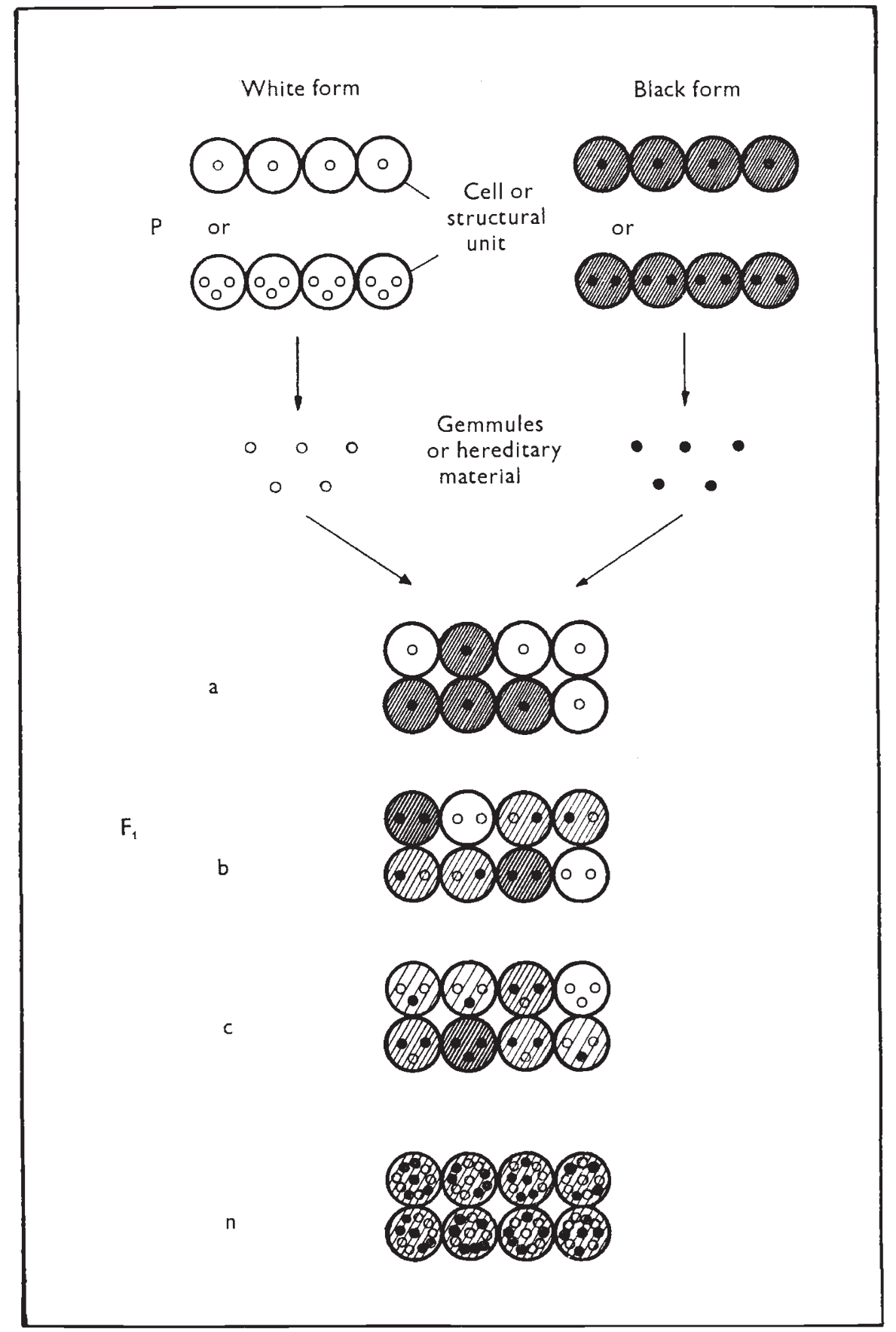

Fig. 1.-To illustrate some points made in a letter from Galton to Charles Darwin. In $\mathbf{F}_{1}$ (a), which refers to (1) of Galton's letter, it is assumed that each structural unit or cell, identical with the organic unit, proceeds from the development of one gemmule. In ( $n)$, which refers to (2) of Glaton's letter, each structural unit or cell, identical with the organic molecule, has " been due to the development ... of a group of gemmules, in which the black and white species would ... be equally numerous ". Cases b and c are intermediate and postulate that the structural unit is due to the development of two (b) or three (c) gemmules. 
not refer to the relative frequencies of classes in the $F_{2}$ progeny from a cross between pure lines. Galton's ratio refers to the relative frequencies of white, grey and black structural units (or cells) which constitute the $\mathrm{F}_{\mathbf{1}}$ grey hybrid individual. Indeed Galton himself wrote that "the hybrid between white and black forms was exactly intermediate, viz. gray-thenceforward forever".* Moreover, the last part of the letter: "If there were two gemmules only ... Pascal's triangle" is actually the development of the preceding sentence: "The larger the number of gemmules in each organic molecule, the more uniform will the tint of grayish be in the different units of structure". The strict correspondence between the elements of these two propositions leaves no doubt about the sense of "cases", which refer to the units of structure in a $\mathbf{F}_{\mathbf{1}}$ hybrid individual.

Secondly, was Galton really reasoning about the basic assumption that " inheritance is due to a finite number of persistent particles". In other words, did he ever assume the first Mendelian law of alternative inheritance? This is doubtful. Indeed Galton's argument is based on the pangenetic assumption that each cell of the organism gives off " minute granules, or atoms, or gemmules". Were these gemmules thought to persist with their original characteristics from one generation to the next? More precisely: what kind of hereditary material, or gemmules, will the $F_{1}$ hybrids produce? (see fig. $1, \mathrm{~F}_{1}$ : a, b, c, n). As far as we know nowhere does Galton go into this important question.

"The inception of an important branch of science is seldom traceable to a single work of a single investigator. This is possible with genetics. Genetics takes its rise from the work of Gregor Johann Mendel " (Dobzhansky, 1964). We believe that Sir Francis Galton's letter, in spite of its interest, does not invalidate this assertion.

\title{
REFERENCES
}

DOBZHANSKy, TH. 1964. The Mendel centennial. The Rockefeller Institute Review, 2, 1-6. OLBY, R. C. 1965. Francis Galton's derivation of Mendelian ratios in 1875. Heredity, 20, 636-638.

OL.BY, R. C. 1966. Origins of Mendelism. Constable, London. 204 pp.

\section{GALTON'S RATIOS}

\author{
R. C. OLBY \\ Botany School, Oxford
}

Received 25.ix.67

IN interpreting statements from the past it is, admittedly, all too easy to read into them with the aid of hindsight what is not really there. At the same time it is only just to give recognition to those who adumbrate a fundamental concept.

* One could suppose that the words " thenceforward forever" were used by Galton to express the idea that the greyish character would persist in the sexual offspring of the $F_{1}$ hybrids. This is not the case. These words refer to the vegetative multiplication of the hybrid and form part of Galton's answer to a precise statement of Darwin's, that "If two plants are crossed, it often or rather generally happens that every part of (the) stem, leafeven the hairs-and flowers of the hybrid are intermediate in character; and this hybrid will produce by buds [our italics] millions on millions of other buds all exactly reproducing the intermediate character". 